renders difficult or impossible the proper filtering action of this part of the cornea.

One of us has observed this remarkable clinical picture once only. We are convinced other less obvious cases have been over-looked. In the future we shatl be on the look out for cases of this type, and now that attention has been drawn to it, perhaps others will report similar cases. A suggested name for this affection might be "primary symmetrical interstitial fatty corneal dystrophy with lipoidal arc, due to nephrotic lipaemia." Further investigations by clinicians and biochemists will be required.

\title{
A CASE OF MUSTARD GAS KERATITIS UNDER CONSTANT OBSERVATION FOR A PERIOD OF TWENTY YEARS
}

\author{
BY
}

\author{
T. L. DE COURCY
}

IIIER POO'L

IN a recent article in your journal by Miss Mann and Dr. Pullinger the authors expressed regret that we had few details of the treatment given to the earlier cases of delayed mustard gas keratitis. As few ophthalmologists can have had the opportunity of keeping in close touch with a case of this dread disease for a period of over twenty years, a few observations on its course, the treatment given - harmful or otherwise-and the gradual adaptation of the different therapeutic aids as they became available, may be of interest. Possibly the deductions drawn, though of no scientific value, may be helpful as to what to avoid and what to make use of in the treatment of any cases which may still develop even after so long a period.

Even now there is much to learn about delayed mustard gas keratitis - the reason for varying periods before onset of ulceration ; why, under similar circumstances of infection "one should be taken and the other left"' ; whether focal or general disease may be a factor predisposing the gassed candidate to ulceration; in what measure the concentration of gas affects the issue. Most important of all, will the study of this form of keratitis become mainly academic owing to the stoppage of supply, or are we to visualize the future treatment of a vast throng of patients of both sexes and of all ages?

My patient, F.W.S., is now a man, aged 62 years, still an imposing figure, six feet two or three inches in height and proportionately built. Before the world war he was a County tennis 
player and an outdoor man in every sense. He had an excellent war record, winning the M.C. and before the war ended was second in command of his regiment. What is more he is a man of great intelligence, holding an important business position, and this intelligence he has used throughout his treatment in noting any fresh symptoms or any harmful reaction to treatment, and in his wholehearted co-operation which has led to any measure of success achieved up to the present.

It was his reaction to games that induced him to consult me in the early summer of 1922 . He " could not stand the light as well as he used to; he could not follow the flight of a golf ball or judge the distance to the hole; he had just been beaten 6-0 6-0 in a tennis tournament by a man to whom he used to give points." He " knew that in the early forties he could not expect to play games as well as formerly, but why this sudden deterioration within the last month or two "?

In May 1918 a gas shell had burst at a distance of thirty or forty yards when "at rest ". in the back area, and he thought some of the actual fluid entered his eyes. He described the usual symptoms of acute gas poisoning-treated at Base and afterwards English Hospitals for some months. In August 1918 he was passed by a Medical Board and again sent out to France, but he asked the Board to make a note that his sight was not so good as before.

On demobilization he repeated that he was still not seeing so acutely and was again sent to a Medical Board. He states that his early reception. was distinctly unfriendly till the ophthalmologist on the Board had made his examination, after which the atmosphere improved. He was then informed that everyone who had been gassed was making a claim regarding eyes, but that he was evidently one of the very few who had really suffered and was granted a 15 per cent. pension.

My examination revealed slight scarring of the corneae just below the pupil (rather more marked in the right eye), a small degree of hypermetropic astigmatism and corrected vision of $6 / 12$ $6 / 6$, but no visible acute condition apart from intolerance to light.

In my opinion the process of disintegration of the corneae had then started with these subjective symptoms, as during the next three years I had to change his glasses at intervals of less than a. year owing to increasing astigmatism which gradiually assumed the mixed variety. For example, early in 1925 his refraction was :-

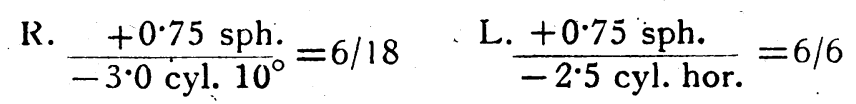

His accommodation was also poorer than one expected. 
It was unfortunate that during this period the slit-lamp was not part of the armament of the ordinary ophthalmic surgeon, but later on with its advent, I was able to take a more intelligent interest in my patient.

At this period, however, there was no evident vascularization of the corneae and no. slit-lamp to detect the formation of crystals as described in Miss Mann's article. It was only on the evidence of the rapid changes in refraction, indicating degeneration of the corneae, that later on one felt certain that the pre-ulcerative phase of gas keratitis had started when the patient first consulted me. It must be remembered that during this stage the prospect of future ulceration was not in my mind as there were at that time very few such cases described in this country.

The next stage in my patient's corneal history began late in 1925 when on his honeymoon in the Riviera (he was also a late starter in matrimony) the first attack of ulceration started in his right eye causing his precipitate return home. The left eye was not attacked until 1926 and he never exceeded a period of more than a year without an attack in one or the other eye till 1937, since which date no serious ulceration has taken place.

Each attack lasted from a few weeks to three months varying in severity, each leaving behind fresh corneal destruction which was gradually encroaching on to the pupil areas. The ulcers were not large but generally multiple and involving the deeper corneal layers. The rugged scar areas left after each attack reduced the vision in the right eye so much that I ceased to try to correct it by glasses in 1928. Till 1938 he relied chiefly on his left eye and reached the stage in which he could only see to read with glasses when the book was held close to the eye.

It is only necessary to mention two or three other clinical points. In 1924, towards the end of the pre-ulcerative stage, it was noted that both corneae were anaesthetic. It may be the practice of some ophthalmic surgeons to test the sensitivity of the cornea of all their patients coming for refraction, but after all life is short. My patient had made no complaint of any inconvenience to suggest such a condition, and it was only the repeated refractive changes which induced me to explore further the state of the corneae. It would now be interesting to know if the corneae had been anaesthetic since 1918 .

Two very subtle sources of danger were exposed-that of the possibility of injury by foreign, bodies, and still more (in this particular case) from the friction of occasional ingrowing laslaes. This latter source was the cause of several attacks of ulceration, which have been less frequent since the patient has attended regularly, every month or so, to have any suspicious lashes removed. 
Crystals in the substance of the corneae were noted soon after the first slit-lamp examination-in the late 1920's. Cholesterin crystals were then plentiful and long neèdle-like clear crystals were also seen in abundance. Latterly cholesterin deposits have been absent or very rare.

Blood vessels encroaching on the cornea were present even in the earlier stages, but not in leashes-mainly single vessels which in the earlier stages did not give much trouble. It would be interesting now to have had more precise notes as to their appearance and their distribution in the cornea after crossing the limbus, as a comparison with the cases now being seen. What were noted as "bullae" were of frequent occurrence on the surface of the corneae.

Later and particularly in the last two years three.small " islets ", of blood vessels horizontally across the centre of the pupil have interfered with the vision of the left eye. Their treatment will be referred to later.

Treatment_-Not appreciating at first that gassed corneae should not be treated in any way differently from ordinary corneal ulceration, the usual methods were applied and the first two attacks were probably prolonged for that reason. It was soon apparent that carbolizing the ulcers did definite harm and that such drugs as atropine, dionine, quinine and zinc applied in anything like their usual strength acted as a source of irritation. I referred my patient to Sir William Lister who induced me to curb my over enthusiastic treatment, and in preaching the gospel of masterly inactivity - at any rate as regards drugs - helped me considerably in the treatment of this case. It is interesting to note that sixteen or seventeen years later Miss Mann hints at the same doctrine in the article previously referred to. Weak solutions of the above drugs and many others were made use of and the usual antiseptics applied, but Locke's solution has been the sheet anchor in his local treatment. Cod liver oil and parolein were also helpful. Probably had saline and oily solutions been used alone, which would have needed some courrage at that time, the result would have been-equally effective.

On three or four occasions I performed tarsorrhaphy of the Wheeler type, once involving a period of one year in the left eye, twice for at least six months in the right. During the occlusion of the eye he had no attacks of ulceration, but after the lids were opened ulceration took place fairly soon. The results of tarsorrhaphy were on the whole disappointing, and in the light of present methods probably would be unnecessary.

$\mathrm{X}$-rays were used therapeutically in 1936 , as by this time the state of the corneae was causing grave anxiety.. On the whole $\mathrm{X}$-ray treatment may be said to have cut short the ulcerative 
periods and certainly did not irritate the eyes. At a stage when the battle appeared to be going against us it was a relief to find any treatment which enabled the eyes to hold their own, but X-ray must be applied by an experienced radiologist.

Whatever the eventual outcome may be of this hardly fought battle there was a decided stand in 1937 and since then a period of renewed hope resulting in improved busineșs and social life. It came about through news of a friend of the patient's whose corneal ulceration had greatly benefited by the application of shortwave diathermy under the direction of Jess of Leipzig. We decided it was worth a trial and this decision proved a very wise one, as a lengthy spell of treatment gave results that one could scarcely have hoped for. The electric heater had been used for years with benefit, but this localized heat from the short-wave diathermy, repeated afterwards at Moorfields, and now available in Liverpool, should it be needed again, holds prospects of success far ahead of anything previously tried in this patient's case. There has been no further attack of severe ulceration since diathermy was first started, and that at a period when things wete going from bad to worse.

For some years my own feeling had been that it would be worth while to try the effect of contact lenses, to improve the much impaired vision and also to shield the cornea, but could not get anyone to agree that it was worth the risk. My patient returned from Germany with " stock" but reasonably well fitting contact lenses which he was able to wear for short periods. I was about to send him to Budapest for fitted lenses when Dr. Dallos came to London, and the lenses supplied by him have proved an enormous success: They can be worn for ten hours or so at a time and though occasionally when irritation of the eyes occurs one or other lens has to be left off for a few days, the general improvement in sight has been miraculous. The right eye which had been almost discarded as a visual organ has enabled him to conduct his business when the left eye was for one reason or another temporarilly out of action, and with the left eye plus contact lens he has recently had $6 / 9$ vision and been able to read newspaper type comfortably.

Incidentally the only other case of mustard gas keratitis which has come under my care, recently developed a severe hypopyon ulcer in his only remaining eye. A large part of the cornea, including the pupil area, became infiltrated with pus and vision was reduced to perception of light. A lengthy period.of shortwave diathermy at the Eye and Ear Infirmary, Liverpool, resulted in a healed but badly scarred cornea, when the odds seemed all in favour of panophthalmitis. Applications to the Ministry of Pensions for the fitting of a contact lens resulted in his removal 
to London where fitting took place at Moorfields and an iridectomy was performed with very satisfactory results.

It is conceivable that the saline contained in the contact lenses is beneficial to the corneae and may be the only treatment required. However difficult it may be to rid our minds of the routine treatment for corneal ulceration I feel convinced that the best treatment - for gassed corneae would be cod liver oil drops and saline, together with diathermy and contact lenses, but this opinion is based on the experience of only two cases. Other factors have of cburse, to be considered and in the case of F.W.S. the recent encroaching of blood vessels on the corneae and the "islets" of vessels over the pupil area were causing concern. On the advice of Miss Mann it was decided to cauterize these vessels at the limbus. As any operative procedure had to be performed under the aegis of the Ministry of Pensions (his pension now being at the 80 per cent. rate) the patient was recently operated on by Mr. Humphrey Neame at Moorfields, who, partly by cautery and partly by the diathermy point cut off a great number of vessels at the limbus, and the islets have practically disappeared-an excellent result. There is no reason why this procedure should not be repeated if necessary in the future, though the reaction has been very marked and one eye remained red for a considerable period.

\section{Conclusions}

The opportunity of being in close touch with a case of delayed mustard gas keratitis for twenty years must be shared by few ophthalmologists and for this reason it may be worth putting on record the clinical features most worthy of note and the main lines of treatment-good and bad-which were tried out, and the vicissitudes of fortune during that period.

Any measure of success attained has been due to the patient's keen intelligence in noticing any abnormal symptom and reporting it at once (I encouraged the use of the telephone), and to his loyal support in every fresh line of treatment, together with the helpful advice and assistance given by many surgeons whose interest was aroused in the patient. What is also very noteworthy, and gives some idea of the character of the patient, is the fact that never once have I heard him bewail his fate.

Risking some inevitable repetition the following points in this case appear to me most noteworthy.

1. To judge from the scarring of the corneae when the patient was first seen, actual ulceration must have taken place at the time of gassing (1918). 
2. Subjective symptoms appeared four years later (1922) with photophobia and report of " bad judgment," in visual efforts.

3. Rapid changes in refraction in the "pre-ulcerative" period of those years (1922-1925) in which degenerative changes presumably took place in the corneae to account for these variations in refraction.

4. Anaesthesia of the corneae first noted in 1924 but probably present since the initial attack. Is anaesthesia always present in delayed gassed corneae?

5. The necessity for constant observations of this particular case in order to remove aberrant lashes and watch for foreign matter which might injure the anaesthetic corneae.

6. The onset of the ulcerative stage seven years after his initial gassing, and its recurrence at intervals during the next twelve years. The moderate vascularization accompanying these attacks.

7. The deposit of cholesterin and other crystals in the corneae in the earlier stages of the disease and their gradual disappearance.

8. Drugs used as drops had to be prepared in much weaker solutions than for ordinary-keratitis. The suggestion is made that oily drops, normal saline, or Locke's solution may have been the only applications necessary for this case in which iritis was never a prominent feature. Pure carbolic must never be used.

9 . The disappointing results of tarsorrhaphy, as soon after reopening the lids ulcerations again took place.

10. The possible good results of X-rays carefully applied.

11. The undoubted benefit of short-wave diathermy.

12. The protection provided to the corneae by fitted contact lenses and the striking increase of visual actuity resulting from their use.

In this connection there should be a word of warning. The actual fitting of the lenses was a very severe strain on the patient and caused slight ulceration. Fitting had to be suspended for some three weeks while the corneae recovered.

13. "The late appearance of "islets" of blood over the pupil areas and their disappearance after peritomy.

-14. The fact that no focus of infection was found in the patient to predispose him to mustard gas keratitis-the usual tests having been made at the time of his first attack of ulceration.

15. Lastly that after twenty adventurous years the patient leads a practically normal social and business life. 